\title{
Comparison between quantitative computed tomography, scintigraphy, and anatomical methods for prediction of postoperative FEV 1 and DLCO: effects of chronic obstructive pulmonary disease status and resected lobes
}

\author{
Masanori Yokoba ${ }^{1,2}$, Tsuyoshi Ichikawa ${ }^{3}$, Shinya Harada ${ }^{2}$, Kazu Shiomi ${ }^{4}$, Masashi Mikubo ${ }^{4}$, \\ Mototsugu Ono ${ }^{4}$, Dai Sonoda ${ }^{4}$, Yukitoshi Satoh ${ }^{4}$, Hironori Hanawa ${ }^{5}$, Katsuhiko Naoki ${ }^{2}$, Masato Katagiri ${ }^{1,2}$ \\ ${ }^{1}$ School of Allied Health Sciences, Kitasato University, Kanagawa, Japan; ${ }^{2}$ Department of Respiratory Medicine, Kitasato University Hospital, \\ Kanagawa, Japan; ${ }^{3}$ Department of Rehabilitation Services, Tokai University Hospital, Tokyo, Japan; ${ }^{4}$ Department of Pulmonary Surgery, Kitasato \\ University Hospital, Kanagawa, Japan; ${ }^{5}$ Department of Radiology, Kitasato University Hospital, Kanagawa, Japan \\ Contributions: (I) Conception and design: M Yokoba, T Ichikawa, M Katagiri; (II) Administrative support: M Yokoba; (III) Provision of study materials \\ or patients: M Yokoba, S Harada, K Shiomi, M Mikubo, M Ono, D Sonoda, Y Satoh, M Katagiri; (IV) Collection and assembly of data: M Yokoba, \\ T Ichikawa, S Harada; (V) Data analysis and interpretation: M Yokoba, T Ichikawa; (VI) Manuscript writing: All authors; (VII) Final approval of \\ manuscript: All authors. \\ Correspondence to: Masanori Yokoba, MD, PhD. Kitasato University, School of Allied Health Sciences, Kitasato 1-15-1, Minami-ku, Sagamihara, \\ Kanagawa 252-0373, Japan. Email: myoko@kitasato-u.ac.jp.
}

Background: Postoperative assessment of pulmonary function is important for estimating the risk of thoracic surgery and long-term disability following pulmonary resection, including predicted postoperative (ppo) forced expiratory volume (FEV) in one second (ppoFEV $\mathrm{F}_{1}$ ) and percent predicted lung diffusion capacity for carbon monoxide (ppo\%DLCO) estimation. The ppo values were compared using four different estimation methods between chronic obstructive pulmonary disease (COPD) and non-COPD patients and according to the resected lobe.

Methods: This prospective study included 59 eligible patients requiring single lobectomy and succeeded in performing pulmonary function tests at 3 and 12 months after lobectomy. The ppoFEV $\mathrm{F}_{1}$ and ppo\%DLCO were compared with poFEV $\mathrm{F}_{1}$ and po\%DLCO obtained at 3 and 12 months after lobectomy. The ppo values were estimated using the four usual methods: the 19-segment anatomical technique (S), perfusion scintigraphy (Q), quantitative CT (CT), and quantitative CT with low attenuation volume $\left(\mathrm{CT}_{\mathrm{LAV}}\right)$ subtraction.

Results: For non-COPD and COPD patients, the smallest mean difference between ppo and po values was observed by $\mathrm{S}$ for $\mathrm{FEV}_{1}$ and \%DLCO. Based on the resected lobe, the smallest mean difference was observed by (I) Q for right upper lobectomy (RUL) excluding \%DLCO at 12 months by S, (II) S for left

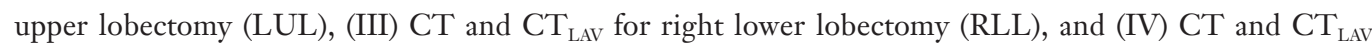
for left lower lobectomy (LLL) at 12 months. The ppo values calculated by $\mathrm{S}$ for RUL (FEV $\mathrm{F}_{1}$ at 3 and

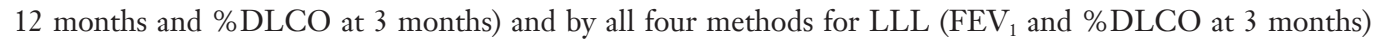
were smaller than the po values.

Conclusions: The $\mathrm{S}$ method is adequate for calculating ppoFEV $\mathrm{F}_{1}$ and ppo\%DLCO when patients are classified as non-COPD and COPD. However, S sometimes overestimates the ppoFEV $\mathrm{F}_{1}$ and ppo\%DLCO when patients are classified according to the resected lobe. The $\mathrm{CT}_{\mathrm{LAV}}$ method may be the method of choice instead of $\mathrm{S}$ for calculating ppoFEV $\mathrm{V}_{1}$ and ppo\%DLCO in patients who undergo lung lobectomy despite the presence or absence of airflow limitation.

Keywords: Thoracic surgical candidate; video-assisted thoracoscopic surgery (VATS); location of the lobe 
Submitted Mar 31, 2020. Accepted for publication Sep 14, 2020.

doi: $10.21037 /$ jtd-20-1280

View this article at: http://dx.doi.org/10.21037/jtd-20-1280

\section{Introduction}

Surgical lung resection is the recommended treatment for non-metastatic, non-small cell lung cancer patients. Postoperative (po) evaluation of pulmonary function is important for estimating the risk of thoracic surgery and long-term disability after pulmonary resection. The guidelines of the European Respiratory Society and the European Society of Thoracic Surgery (ERS/ESTS) recommend the use of the following po values: forced expiratory volume in 1 second $\left(\mathrm{FEV}_{1}\right)$, lung diffusion capacity for carbon monoxide (DLCO), and maximal oxygen consumption ( $\dot{\mathrm{V}}_{2} \max$ ) to estimate the risk of death and cardiopulmonary complications after surgical resection (1). In clinical practice, the most common and widely used functional test is estimation of the predicted postoperative (ppo) $\mathrm{FEV}_{1}$ and DLCO.

In a patient undergoing lobectomy, the "anatomical method" based on the number of segmental bronchi (2) is used to calculate the ppoFEV $\mathrm{F}_{1}$ and ppoDLCO. Currently, other methods, based on scintigraphy or computed tomography (CT) imaging, are considered to estimate po respiratory function more accurately (3-8). However, these investigations do not focus on whether patients were diagnosed with chronic obstructive pulmonary disease (COPD) or were non-COPD, or the location of the resected lobe, although lung expansion and alternation of pulmonary function after lobectomy were reported to differ according to the volume of emphysematous lung parenchyma $(9,10)$ and the area of the resected lobe $(11,12)$.

The primary objective of this prospective study was to evaluate $\mathrm{ppoFEV}_{1}$ and ppo\%DLCO with four different estimation methods between non-COPD and COPD patients and according to the resected lobe. These estimates were compared to $\mathrm{FEV}_{1}$ and \%DLCO measured at 3 and 12 months postoperatively (poFEV ${ }_{1}$ and po\%DLCO) after single lobectomy.

We present the following article in accordance with the STROBE reporting checklist (available at http://dx.doi. org/10.21037/jtd-20-1280).

\section{Methods}

\section{Patients}

Eligible patients were those scheduled to undergo single lobectomy by video-assisted thoracoscopic surgery (VATS) at Kitasato University Hospital in Kanagawa, Japan, between December 11, 2013 and March 28, 2016, and those who succeeded in performing pulmonary function tests at 3 and 12 months after lobectomy. This study was approved by the Kitasato University Medical Ethics Organization on June 28, 2013 (approval number: KMEO B13-110). All patients were prospectively enrolled in this study after obtaining their written informed consent. The study was conducted in accordance with the Declaration of Helsinki (as revised in 2013). Using the "Algorithm for Thoracotomy and Major Anatomical Resection" (2), high-risk patients (ppoFEV ${ }_{1}$ or ppo\%DLCO $<30 \%$ ) were excluded as candidates for surgical treatment in our hospital. Patients were given an incentive spirometer before surgery according to the standard protocol for thoracic surgery in our hospital. However, they did not undergo focused perioperative or pulmonary rehabilitation before or after the surgery. For smoking status, a patient who had smoked more than 100 cigarettes in their lifetime and had smoked in the last 28 days before preoperative pulmonary function testing, was defined as a "current smoker." A patient who had smoked more than 100 cigarettes in their lifetime but had not smoked in the last 28 days before preoperative pulmonary function testing was defined as a "former smoker," and a patient who had smoked less than 100 cigarettes in their lifetime and did not currently smoke was defined as a "nonsmoker."

\section{Pulmonary function tests}

Pulmonary function tests including slow vital capacity (SVC), forced vital capacity (FVC), $\mathrm{FEV}_{1}$, and DLCO were performed according to the guidelines of the Japanese Respiratory Society (13), and spirometric reference values of SVC, FVC, $\mathrm{FEV}_{1}$, and $\mathrm{FEV}_{1} / \mathrm{FVC}$ for Japanese adults 
were calculated using the LMS (lambda, mu, sigma) method (14). DLCO was corrected according to the patient's haemoglobin level. To determine \%DLCO, normal values of DLCO reported by Burrows et al. (15) were applied.

$\mathrm{FEV}_{1}$ and \% DLCO were evaluated before the operation and at 3 and 12 months postoperatively with the same equipment and technique. We decided to perform the pulmonary function tests at 3 months postoperatively for the short-term follow-up. In some patients, the symptoms and pulmonary function kept improving until 12 months postoperatively. Thus, we decided to perform the pulmonary function tests at 12 months for the longterm follow-up and compared them to the ppo values.

A preoperative pulmonary function test was performed within one month prior to the surgery. Classification of airflow limitation severity in COPD was defined with postbronchodilator predicted $\mathrm{FEV}_{1}$ according to the Global Initiative for Chronic Obstructive Lung Disease (GOLD) criteria (16). Among patients with airflow limitation $\left(\mathrm{FEV}_{1} /\right.$ FVC $<0.70$ ), some patients who were previously diagnosed with COPD and had been started on treatment for their COPD, refused to undergo the bronchodilator test to assess their airflow limitation severity. Other patients that were not diagnosed with an obstructive ventilatory defect were started on treatment with a bronchodilator [inhaled long-acting muscarinic antagonist (LAMA) and/or longacting beta-agonist (LABA)] without a bronchodilator test. The preoperative pulmonary function test was repeated approximately 2 weeks after receiving treatment with a bronchodilator, which was maintained throughout the study. The patients who remained with airflow limitation $\left(\mathrm{FEV}_{1} / \mathrm{FVC}<0.70\right)$ under the bronchodilator treatment were regarded as having COPD, and their airflow limitation severity was assessed on the basis of results of the second preoperative pulmonary function test. The percentage predicted $\mathrm{FEV}_{1}$ and DLCO were expressed as the percentage of the predicted values for age, sex, and height.

\section{Computed tomography (CT) scanning}

With the patient in the supine position, helical CT scans with $1.25-\mathrm{mm}$ high-resolution CT images of lung during a deep inspiratory breath hold using 64-detector row CT scanners (Optima 660; GE Healthcare, Tokyo, Japan) with $512 \times 512$ matrices, $1.25-\mathrm{mm}$ collimation, and a scan time of $0.5 \mathrm{~s}$ at $120 \mathrm{kVp}$ and $270 \mathrm{~mA}$ were obtained. Since this was a routine practice, patients were not exposed to any additional radiation for the purpose of measuring the radiological parameters in this study.

\section{Image interpretation and data analysis}

Three-dimensional volume rendering lung images were created using a commercially available, user-friendly imaging software program (Ziostation $2^{\circledR}$; Ziosoft, Inc., Tokyo, Japan). Threshold limits of -600 to $-1,024 \mathrm{HU}$ were applied to segment both lungs entirely and to exclude the soft tissues surrounding the lungs and the large vessels, atelectasis, fibrosis, and tumours within the lung. The volume of a lung segmented by a certain threshold limit can be readily obtained with the imaging software program. The volume of the lungs ( -600 to $-1,024 \mathrm{HU}$ ) was designated as the total lung volume (TLV). The lungs were divided into two areas: low-attenuation areas that represented emphysematous lung tissue (<-950 HU), and normalattenuation areas $(-600$ to $-950 \mathrm{HU})$ that represented normal lung fields. The volume and the low-attenuation volume (LAV) for each lobe and lung were calculated. \%LAV of the resected lobe was calculated by dividing [LAV of the resected lobe] by [volume of the resected lobe] and \%LAV of lung was calculated by dividing [LAV of the lung] by [volume of the lung] (12).

\section{Prediction of the postoperative pulmonary function}

For $\mathrm{FEV}_{1}$ and \%DLCO, the ppo values were all calculated from pre-operative values modified by estimation of lost function using 4 techniques: an algorithmic method based on preoperative spirometry, a method based on the lung perfusion scintigraphy assessed by technetium-99m macroaggregated albumin (99mTc-MAA), and 2 methods based on quantitative CT.

The Algorithmic method based on preoperative spirometry was (I) calculated based on the number of functioning/unobstructed segments to be removed during surgery $(S)$ : ppo value $=$ preoperative value $\times$ $(1-y / z)$, with $[y]$ the number of functional or unobstructed lung segments to be removed and $[\mathrm{z}]$ the total number of functional segments $(1,2)$.

(II) The method based on perfusion scintigraphy (Q) was as follows: ppo value $=$ preoperative value $\times(1-$ functional contribution of perfusion of the region to be removed). This is the standard calculation formula for thoracic surgery in our hospital (17).

(III) The methods based on quantitative CT estimated 
the ppo value according to the following formula (CT): ppo value $=$ preoperative value $\times\{1-(\alpha / \gamma)\}$, with $[\alpha]$ the regional functional lung volume of the lobe to be removed, and $[\gamma]$ the lung volume (7); and (IV) quantitative CT with LAV $\left(\mathrm{CT}_{\text {LAV }}\right)$ : ppo value $=$ preoperative value $\times$ $(1-[\{\alpha \times(1-\beta)\} / \gamma])$, with $[\alpha]$ the regional functional lung volume of the lobe to be removed, $[\beta]$ the fraction of the LAV of the lobe to be removed, and $[\gamma]$ the lung volume (18).

These four ppo values were compared to the actual po values obtained at 3 and 12 months after lobectomy.

\section{Statistical analysis}

To evaluate the characteristics of the patients, preoperative data were compared between the non-COPD and COPD groups using the Mann-Whitney $U$ test (one-tail).

Agreement between the ppo values and po values of $\mathrm{FEV}_{1}$ and \%DLCO obtained at 3 and 12 months after lobectomy were analysed using the Bland-Altman method (19) by plotting the difference between the paired po and ppo values according to COPD, non-COPD and the resected lobe. Limits of agreement (LOA) were defined as mean of difference $\pm 2 \mathrm{SD}$. The mean values for $\mathrm{FEV}_{1}$ and $\%$ DLCO were also compared between the ppo and po values using the determination coefficient. The mean differences between the ppo and po values are expressed as mean standard deviation for each method. A P value $<0.05$ was considered statistically significant. All statistical analyses were performed with EZR (Saitama Medical Center, Jichi Medical University), which is a graphical user interface for $\mathrm{R}$ (The R Foundation for Statistical Computing, version 3.0.2) (20) based on a modified version of $\mathrm{R}$ commander (version 2.4-0).

\section{Results}

\section{Preoperative data}

Of the 75 patients eligible for VATS lobectomy, 16 were excluded because of chylothorax $(n=1)$, pyothorax $(n=2)$, lung cancer recurrence $(n=3)$, cerebral vascular infarction $(\mathrm{n}=1)$, renal cell carcinoma $(\mathrm{n}=2)$, and withdrawal of consent $(\mathrm{n}=7)$. Finally, 59 patients (mean age, 69.0 \pm 8.2 years; range, 43-84 years) with complete pulmonary function assessment were included in this study. The indications for lobectomy were adenocarcinoma $(n=44)$, squamous cell carcinoma $(\mathrm{n}=10)$, adenosquamous carcinoma $(\mathrm{n}=1)$, small-cell carcinoma $(\mathrm{n}=1)$, large cell neuroendocrine carcinoma $(n=1)$, pleomorphic carcinoma $(n=1)$, and benign lymphoproliferative disorder $(\mathrm{n}=1)$. Preoperative patient characteristics are described in Table 1. Current and former smokers discontinued their smoking habits before surgery. Most of the patients, including 16 of 20 non-COPD patients and 17 out of 20 COPD patients, discontinued smoking more than 4 weeks prior to the preoperative pulmonary function tests. The remaining 7 out of 40 patients discontinued smoking just after the first set of pulmonary function tests. According to the guidelines for lung function testing (13), all patients discontinued smoking 24 hours prior to DLCO measurements of the first set of pulmonary function tests to prevent smoking from affecting the results of the test $(21,22)$. Thereafter, none of them resumed smoking.

Body weight was higher in the COPD group than in the non-COPD group. However, $\mathrm{FEV}_{1}, \mathrm{FEV}_{1} / \mathrm{FVC}$, \% FEV $\mathrm{F}_{1}$ $\% \mathrm{DLCO}$, and \%DLCO $/ \mathrm{V}_{\mathrm{A}}$ were lower in the COPD group than in the non-COPD group (Table 1).

Both mean \% LAV values of the resected lobe and lung were higher in the COPD than in the non-COPD group. There was no difference between the groups for the LAV ratio between the resected lobe and the lung (LAV of the resected lung/LAV of the lung).

\section{VATS for lobectomy and postoperative pain}

Pure VATS using a 3-port technique was performed in 13 patients (9 non-COPD, 4 COPD patients) by four thoracic surgeons, and Assist VATS was performed in 46 patients by seven thoracic surgeons. Pure VATS was performed for 6 right upper lobectomies (RUL), 6 right lower lobectomies (RLL), and 1 left lower lobectomy (LLL). No patient underwent conversion from VATS to open thoracotomy. Epidural analgesia was used during the surgeries. All patients received patient-controlled epidural analgesia (PCEA) until postoperative day (POD) 2 or 3. Thereafter, non-steroidal anti-inflammatory drugs and/or opioid pain medications, such as tramadol hydrochloride, were administered during the hospitalization period, on an "as required" basis until 8 weeks after surgery. The pulmonary function tests performed at 3 months and 12 months after surgery were performed under pain-free conditions and no patient complained of postoperative pain during the pulmonary function tests. 
Table 1 Preoperative characteristics of patients

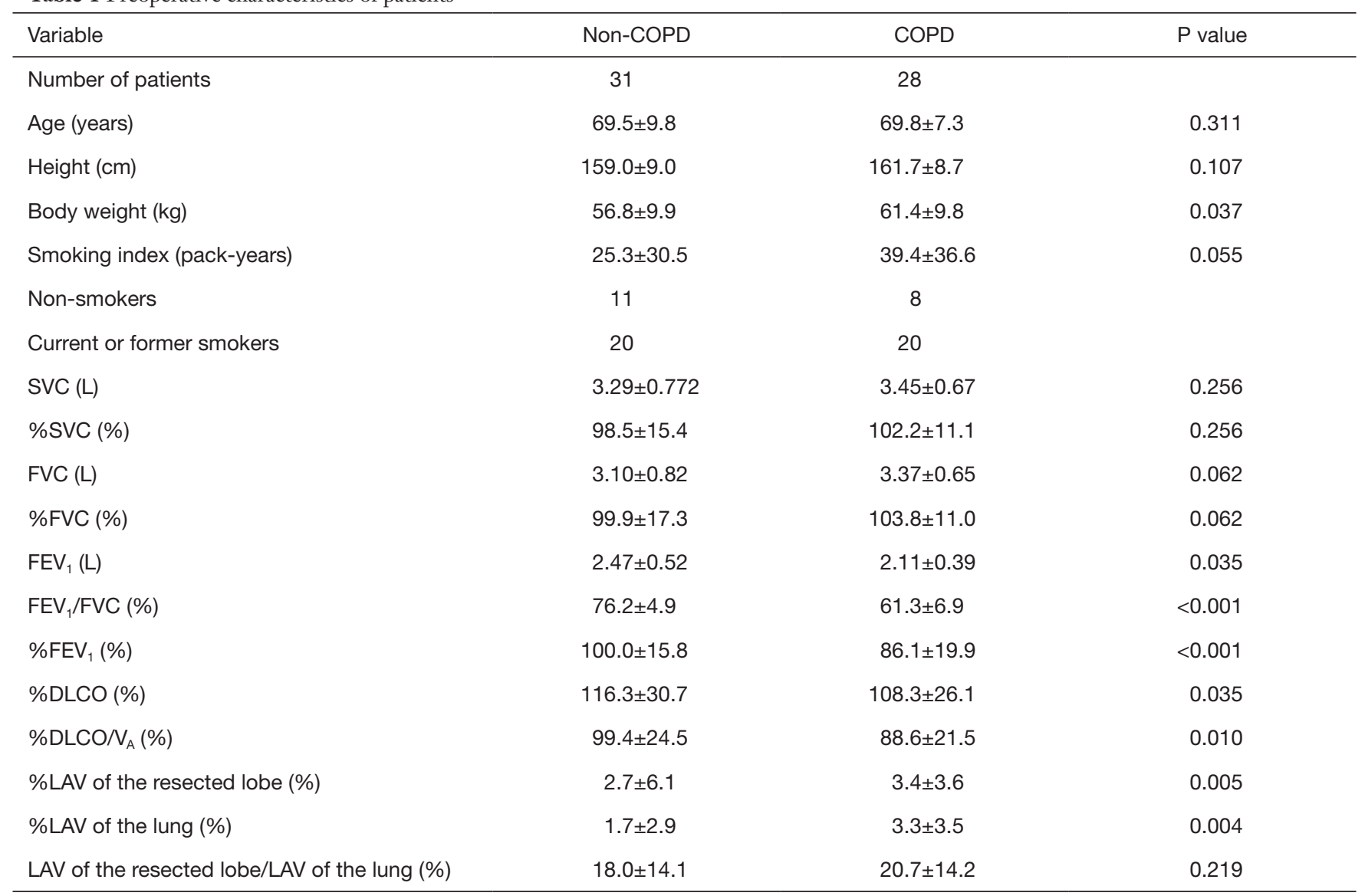

Values are represented mean \pm SD. A P value of less than 0.05 was considered statistically significant. COPD, chronic obstructive pulmonary disease; \%DLCO, percent predicted lung diffusion capacity for carbon monoxide; \%DLCO/ $\mathrm{N}_{\mathrm{A}}$, percent predicted lung diffusion capacity for carbon monoxide divided by the alveolar volume; $\mathrm{FEV}_{1}$, forced expiratory volume in one second; FVC, forced vital capacity; LAV, low-attenuation volume; SVC, slow vital capacity.

\section{Pulmonary function and symptoms after lobectomy}

One GOLD 1 COPD patient who underwent LLL developed pneumonia on POD 6. He was treated with antibiotics for 7 days and had an uneventful recovery. $\mathrm{He}$ required low-flow oxygen therapy but did not require mechanical ventilation. Other patients did not suffer from postoperative complications such as pneumonia and did not require mechanical ventilation postoperatively. One GOLD 1 and two GOLD 2 COPD patients who had LUL required domiciliary oxygen therapy at the time of hospital discharge, which was withdrawn within 3 months after surgery and the three of them had quit smoking several years ago. No patients required oxygen therapy following pulmonary function tests postlobectomy.

\section{Predicted postoperative and actual postoperative values at 3 and 12 months after lobectomy}

The ppo $\mathrm{FEV}_{1}$ and \%DLCO and mean volume differences with po values were calculated for each method of assessment.

\section{Non-COPD and COPD patients}

The ppoFEV ${ }_{1}$ calculated by $\mathrm{S}, \mathrm{Q}, \mathrm{CT}$, and $\mathrm{CT}_{\mathrm{LAV}}$, the mean differences between po and ppo (bias) and LOA and determination coefficient are shown in Table 2. In the nonCOPD group, $\mathrm{S}$ showed the smallest mean difference of $\mathrm{FEV}_{1}$ at 3 and 12 months after lobectomy. In the COPD group, $\mathrm{S}$ again showed the smallest mean difference of $\mathrm{FEV}_{1}$ at 3 and 12 months after lobectomy.

The ppo\%DLCO calculated by S, Q, CT, and $\mathrm{CT}_{\mathrm{LAV}}$, 
Table 2 ppoFEV $_{1}$, mean differences between the ppo and po values at 3 and 12 months after lobectomy and the limit of agreement

\begin{tabular}{|c|c|c|c|c|c|c|c|}
\hline $\begin{array}{l}\text { Method of } \\
\text { estimation }\end{array}$ & $\operatorname{ppoFEV}_{1}(\mathrm{~L})$ & $\begin{array}{c}\text { Mean difference } \\
\text { with poFEV }(\mathrm{L}) \text {, } \\
3 \mathrm{M}\end{array}$ & $\begin{array}{l}\text { Limit of } \\
\text { agreement } \\
\text {-2SD, 2SD (L) }\end{array}$ & $\begin{array}{l}\text { Determination } \\
\text { coefficient }\end{array}$ & $\begin{array}{c}\text { Mean difference } \\
\text { with poFEV }{ }_{1}(\mathrm{~L}) \text {, } \\
12 \mathrm{M}\end{array}$ & $\begin{array}{l}\text { Limit of agreement } \\
\quad-2 S D, 2 S D(L)\end{array}$ & $\begin{array}{l}\text { Determination } \\
\text { coefficient }\end{array}$ \\
\hline S & $1.89 \pm 0.49$ & $0.02 \pm 0.23$ & $-0.43,0.49$ & $R^{2}=0.73 ; P<0.01$ & $0.11 \pm 0.27$ & $-0.49,0.67$ & $R^{2}=0.69 ; P<0.01$ \\
\hline$Q$ & $1.87 \pm 0.49$ & $0.05 \pm 0.21$ & $-0.37,0.47$ & $R^{2}=0.75 ; P<0.01$ & $0.13 \pm 0.26$ & $-0.46,0.69$ & $R^{2}=0.71 ; P<0.01$ \\
\hline $\mathrm{CT}_{\text {LAV }}$ & $1.88 \pm 0.51$ & $0.03 \pm 0.22$ & $-0.40,0.47$ & $R^{2}=0.79 ; P<0.01$ & $0.12 \pm 0.28$ & $-0.50,0.69$ & $R^{2}=0.74 ; P<0.01$ \\
\hline \multicolumn{8}{|l|}{ COPD } \\
\hline $\mathrm{S}$ & $1.68 \pm 0.30$ & $0.08 \pm 0.31$ & $-0.55,0.7$ & $R^{2}=0.44 ; P<0.01$ & $0.12 \pm 0.34$ & $-0.56,0.79$ & $R^{2}=0.36 ; P<0.01$ \\
\hline$Q$ & $1.67 \pm 0.32$ & $0.09 \pm 0.31$ & $-0.52,0.7$ & $R^{2}=0.45 ; P<0.01$ & $0.13 \pm 0.34$ & $-0.55,0.8$ & $R^{2}=0.35 ; P<0.01$ \\
\hline
\end{tabular}

Values are represented as mean $\pm \mathrm{SD}$. COPD, chronic obstructive pulmonary disease; $\mathrm{FEV}_{1}$, forced expiratory volume in one second; LAV, low-attenuation volume; Limit of agreement, mean \pm 2SD; M, months; po, postoperative value; ppo, predicted postoperative value.

Table 3 ppo\%DLCO, mean differences between the ppo and po values at 3 and 12 months after lobectomy and the limit of agreement

\begin{tabular}{|c|c|c|c|c|c|c|c|}
\hline $\begin{array}{l}\text { Method of } \\
\text { estimation }\end{array}$ & $\begin{array}{c}\text { ppo\%DLCO } \\
(\%)\end{array}$ & $\begin{array}{c}\text { Mean difference } \\
\text { with po\%DLCO } \\
\text { (\%), 3M }\end{array}$ & $\begin{array}{l}\text { Limit of } \\
\text { agreement -2SD, } \\
\text { 2SD (\%) }\end{array}$ & $\begin{array}{c}\text { Determination } \\
\text { coefficient }\end{array}$ & $\begin{array}{c}\text { Mean difference } \\
\text { with po\%DLCO } \\
\text { (\%), } 12 \mathrm{M}\end{array}$ & $\begin{array}{l}\text { Limit of } \\
\text { agreement -2SD, } \\
\text { 2SD (\%) }\end{array}$ & $\begin{array}{c}\text { Determination } \\
\text { coefficient }\end{array}$ \\
\hline $\mathrm{s}$ & $97.0 \pm 23.7$ & $0.9 \pm 15.2$ & $-28.80,31.39$ & $R^{2}=0.62 ; P<0.01$ & $10.7 \pm 15.8$ & $-20.50,43.10$ & $R^{2}=0.60 ; P<0.01$ \\
\hline $\mathrm{Q}$ & $95.7 \pm 22.4$ & $2.2 \pm 14.5$ & $-26.18,31.27$ & $R^{2}=0.62 ; P<0.01$ & $12.0 \pm 15.4$ & $-18.39,43.49$ & $R^{2}=0.64 ; P<0.01$ \\
\hline $\mathrm{CT}_{\text {LAV }}$ & $96.4 \pm 23.5$ & $1.4 \pm 14.4$ & $-27.67,31.06$ & $R^{2}=0.64 ; P<0.01$ & $11.2 \pm 14.8$ & $-19.10,42.5$ & $R^{2}=0.67 ; P<0.01$ \\
\hline \multicolumn{8}{|l|}{ COPD } \\
\hline $\mathrm{s}$ & $86.4 \pm 21.5$ & $1.8 \pm 12.8$ & $-23.77,27.37$ & $R^{2}=0.70 ; P<0.01$ & $7.6 \pm 11.7$ & $-15.87,31$ & $R^{2}=0.76 ; P<0.01$ \\
\hline$Q$ & $85.7 \pm 21.6$ & $2.4 \pm 13.1$ & $-23.69,28.58$ & $R^{2}=0.72 ; P<0.01$ & $8.2 \pm 12.2$ & $-16.08,32.5$ & $R^{2}=0.76 ; P<0.01$ \\
\hline
\end{tabular}

Values are represented as mean \pm SD. COPD, chronic obstructive pulmonary disease; \%DLCO, percent predicted lung diffusion capacity for carbon monoxide; LAV, low-attenuation volume; Limit of agreement, mean \pm 2 SD; M, months; po, postoperative value; ppo, predicted postoperative value.

mean differences between po and ppo, and LOA and determination coefficient are shown in Table 3. In the nonCOPD group, S showed the smallest mean difference of \%DLCO at 3 and 12 months after lobectomy. In the COPD group $\mathrm{S}$ again showed smallest mean difference of \%DLCO at both 3 and 12 months after lobectomy.

\section{According to resected lobe}

The RUL, right middle lobectomy (RML), RLL, LUL and LLL were performed for 19, 2, 15, 14, and 9 patients, respectively (Table 4). Among these patients, the mean volume of resected lobe, volume percentage ratio of LAV of resected lobe to LAV of the lung (\%), and the volume of 
Table 4 Volume of lobe and segment, and percentage of low-attenuation volume of the resected lobe compared to the lung

\begin{tabular}{|c|c|c|c|c|c|}
\hline & Right upper lobe & Right middle lobe & Right lower lobe & Left upper lobe & Left lower lobe \\
\hline $\begin{array}{l}\text { LAV of the resected lobe/LAV of the } \\
\text { lung }(\%) \text {, mean } \pm \mathrm{SD} \text { (range) }\end{array}$ & $\begin{array}{l}21.1 \pm 17.4 \\
(6.0-73.5)\end{array}$ & $\begin{array}{c}32.5 \pm 8.2 \\
(26.8-38.3)\end{array}$ & $\begin{array}{c}11.9 \pm 8 \\
(3.3-27.4)\end{array}$ & $\begin{array}{l}28.0 \pm 11.1 \\
(15.3-55.7)\end{array}$ & $\begin{array}{c}12.4 \pm 9.2 \\
(2.6-28.5)\end{array}$ \\
\hline $\begin{array}{l}\text { Volume of segment }(\mathrm{L}) \text {, mean } \pm \mathrm{SD} \\
\text { (range) }\end{array}$ & $\begin{array}{c}0.31 \pm 0.1 \\
(0.18-0.54)\end{array}$ & $\begin{array}{c}0.26 \pm 0.24 \\
(0.24-0.28)\end{array}$ & $\begin{array}{l}0.21 \pm 0.059 \\
(0.12-0.28)\end{array}$ & $\begin{array}{l}0.23 \pm 0.06 \\
(0.14-0.35)\end{array}$ & $\begin{array}{l}0.23 \pm 0.08 \\
(0.14-0.36)\end{array}$ \\
\hline
\end{tabular}

Values are represented as mean \pm SD. The volume of segment was calculated by dividing [volume of lobe] by [number of segmental bronchi]. LAV, low attenuation volume; COPD, chronic obstructive pulmonary disease.

each pulmonary segment, which was calculated by dividing [volume of each lobe] by [number of segmental bronchi], are also shown in Table 4. The mean ratio of LAV of each resected lobe/lung varied between $2.6 \%$ and $73.5 \%$. The upper lobes, especially the left upper lobe $(28.0 \%)$, had higher \% LAV values than the lower lobes (11.9 and 12.4\%).

The ppoFEV $V_{1}$ and ppo\%DLCO calculated by S, Q, CT and $\mathrm{CT}_{\mathrm{LAV}}$, mean difference between po and ppo and LOA and determination coefficient are shown in Tables 5 and 6 . The patients with RML were excluded from statistical analysis because of the small number of subjects.

For RUL, Q showed the smallest mean positive difference of $\mathrm{FEV}_{1}$ at 3 and 12 months after lobectomy. $\mathrm{Q}$ also showed the smallest mean positive difference of $\%$ DLCO at 3 months, and S showed the smallest mean difference \%DLCO at 12 months after lobectomy. At both 3 and 12 months after lobectomy, poFEV ${ }_{1}$ was less than $\operatorname{ppoFEV}_{1}$ calculated by S. At 3 months after lobectomy, po\%DLCO was also less than ppo\%DLCO calculated by $\mathrm{S}$.

For RLL, CT and $\mathrm{CT}_{\mathrm{LAV}}$ showed the smallest mean difference of $\mathrm{FEV}_{1}$ at 3 and at 12 months after lobectomy. $\mathrm{CT}_{\mathrm{LAV}}$ also showed the smallest mean difference of $\%$ DLCO at 3 and 12 months after lobectomy.

For LUL, S showed the smallest mean difference of $\mathrm{FEV}_{1}$ at 3 and 12 months after lobectomy. S also showed the smallest mean difference of \%DLCO at 3 and 12 months after lobectomy.

For LLL, the actual $\mathrm{FEV}_{1}$ at 3 months after lobectomy was less than the ppoFEV $V_{1}$ calculated by all 4 methods. In contrast, $\mathrm{CT}$ and $\mathrm{CT}_{\mathrm{LAV}}$ showed the smallest mean difference of $\mathrm{FEV}_{1}$ at 12 months after lobectomy. Similarly, the po\%DLCO was less than the ppo\%DLCO calculated by all four different techniques at 3 months after lobectomy.
The $\mathrm{CT}_{\mathrm{LAV}}$ showed the smallest mean difference of \% DLCO at 12 months after lobectomy.

\section{Quantitative CT with and without low attenuation volume assessment}

For both $\mathrm{FEV}_{1}$ and \%DLCO, $\mathrm{CT}_{\mathrm{LAV}}$ showed a larger ppo value than $\mathrm{CT}$, and $\mathrm{CT}_{\mathrm{LAV}}$ showed a smaller mean difference value than CT in both non-COPD and COPD groups, and in any area of lobe resection (Tables 2,3,5,6).

\section{Discussion}

Pulmonary function has been reported to improve from 3 to 12 months after lobectomy; however, $\mathrm{FEV}_{1}$ and $\%$ DLCO at 12 months after lobectomy were still lower than pre-operative values (12). After lung resection, alterations of pulmonary function are in turn implicated in the development of postoperative complications, which are among the foremost causes of mortality (23). In addition, COPD patients sometimes suffer acute exacerbations which worsen pulmonary function (24). Therefore, excluding the estimation method that provided overestimated ppo values compared to the po values is presumed to be better, because lung surgery candidates selected by overestimated ppo values will have narrow safety margins owing to postoperative complications and acute exacerbations.

Several studies have evaluated the feasibility and accuracy of quantitative CT estimation of ppoFEV $\mathrm{F}_{1}$ and DLCO, confirming the validity of this assessment technique (3-8). However, these previous studies did not focus on whether patients were diagnosed with COPD, or the location of the resected lobe, although the po lung volume and its function may vary depending on $\operatorname{LAV}(9,10)$ and the area of the 
Table 5 ppoFEV $V_{1}$, mean differences between the ppo and po values at 3 and 12 months after lobectomy and the limit of agreement

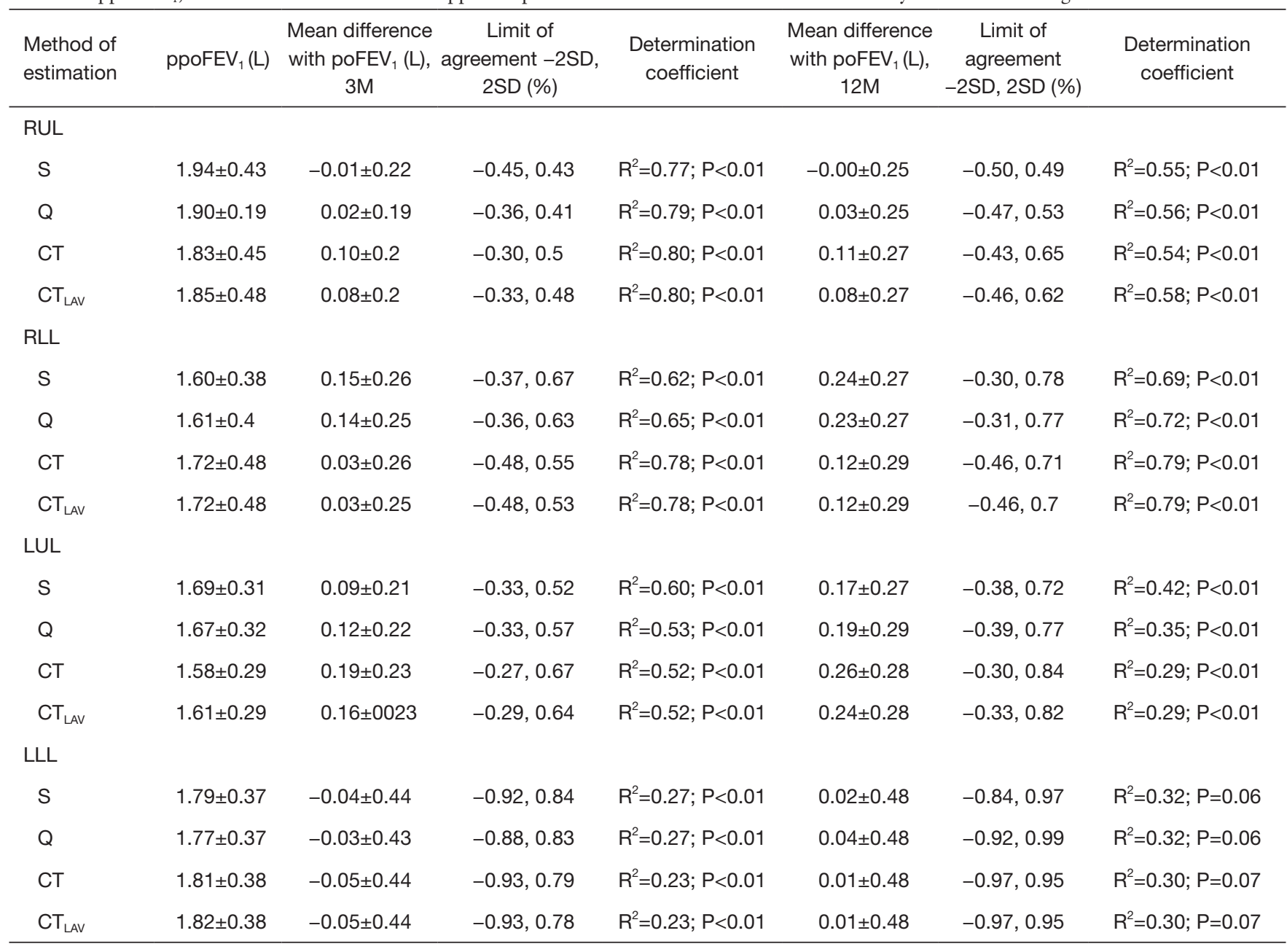

Values are represented as mean \pm SD. RUL, right upper lobectomy; RLL, right lower lobectomy; LUL, left upper lobectomy; LLL, left lower lobectomy. COPD, chronic obstructive pulmonary disease; $\mathrm{FEV}_{1}$, forced expiratory volume in one second; LAV, low-attenuation volume; Limit of agreement, mean \pm 2 SD; $M$, months; po, postoperative value; ppo, predicted postoperative value.

resected lobe $(11,12)$.

\section{Comparison between non-COPD and COPD}

Ueda et al. (4) compared ppoFEV ${ }_{1}$ estimated by quantitative CT and Nakahara formula (25) with the po value measured 3-4 months after surgery for 30 patients undergoing surgical resection of lung cancer, including lobectomy and segmentectomy. Wu et al. (7) compared the quantitative CT ppoFEV $_{1}$, excluding emphysematous lesions, with perfusion scintigraphy based on preoperative spirometry and the po values were measured 3 months after the surgery for 44 non-COPD patients undergoing surgical resection of lung cancer, including 16 lobectomies and 28 pneumonectomies. They concluded that CT predicted $\mathrm{FEV}_{1}$ reserves at 3-4 months after surgery more accurately than segmental counting or perfusion scintigraphy. Bolliger et al. (5) compared the ppo values of $\mathrm{FEV}_{1}, \mathrm{FVC}$, DLCO, and $\dot{\mathrm{V}}_{2}$ and measured the po values at 6 months after surgery for 30 lobectomies, 4 wedge resections, and 10 pneumonectomies, while the ppo values of each were estimated by quantitative CT, perfusion scintigraphy, number of segments, number of functional segments, and number of subsegments. They concluded that both perfusion scintigraphy and quantitative CT were useful irrespective of the resection, but perfusion scintigraphy-based results were the most accurate. 
Table 6 ppo\%DLCO, mean differences between the ppo and po values at 3 and 12 months after lobectomy and the limit of agreement

\begin{tabular}{|c|c|c|c|c|c|c|c|}
\hline $\begin{array}{l}\text { Method of } \\
\text { estimation }\end{array}$ & $\begin{array}{c}\text { ppo\%DLCO } \\
(\%)\end{array}$ & $\begin{array}{c}\text { Mean difference } \\
\text { with po\%DLCO } \\
\text { (\%), 3M }\end{array}$ & $\begin{array}{l}\text { Limit of agreement } \\
-2 \mathrm{SD}, 2 \mathrm{SD}(\%)\end{array}$ & $\begin{array}{c}\text { Determination } \\
\text { coefficient }\end{array}$ & $\begin{array}{l}\text { Mean difference } \\
\text { with po\%DLCO } \\
(\%), 12 \mathrm{M}\end{array}$ & $\begin{array}{l}\text { Limit of } \\
\text { agreement }-2 \mathrm{SD} \text {, } \\
\text { 2SD (\%) }\end{array}$ & $\begin{array}{l}\text { Determination } \\
\text { coefficient }\end{array}$ \\
\hline $\mathrm{S}$ & $98.7 \pm 25.2$ & $-1.3 \pm 12.8$ & $-26.92,24.23$ & $R^{2}=0.68 ; P<0.01$ & $7.5 \pm 12.9$ & $-18.26,33.34$ & $R^{2}=0.72 ; P<0.01$ \\
\hline $\mathrm{Q}$ & $96.8 \pm 23.2$ & $0.6 \pm 10.9$ & $-21.30,22.45$ & $R^{2}=0.69 ; P<0.01$ & $9.5 \pm 12.1$ & $-14.81,33.73$ & $R^{2}=0.74 ; P<0.01$ \\
\hline $\mathrm{CT}_{\text {LAV }}$ & $93.3 \pm 22.5$ & $4.0 \pm 9.7$ & $-15.44,23.52$ & $R^{2}=0.77 ; P<0.01$ & $12.9 \pm 11.2$ & $-9.39,35.25$ & $R^{2}=0.81 ; P<0.01$ \\
\hline \multicolumn{8}{|l|}{ RLL } \\
\hline S & $90.2 \pm 23.4$ & $8.5 \pm 15.4$ & $-22.29,39.34$ & $\mathrm{R}^{2}=0.43 ; \mathrm{P}<0.01$ & $14.1 \pm 18.0$ & $-21.83,49.99$ & $R^{2}=0.58 ; P<0.01$ \\
\hline Q & $90.3 \pm 23$ & $8.4 \pm 16.3$ & $-24.33,41.02$ & $R^{2}=0.38 ; P<0.01$ & $13.9 \pm 18.7$ & $-23.56,51.37$ & $R^{2}=0.58 ; P<0.01$ \\
\hline \multicolumn{8}{|l|}{ LUL } \\
\hline S & $82.4 \pm 18.4$ & $2.5 \pm 11.6$ & $-20.77,25.71$ & $R^{2}=0.66 ; P<0.01$ & $12.1 \pm 12.8$ & $-13.40,37.62$ & $R^{2}=0.54 ; P<0.01$ \\
\hline Q & $81.3 \pm 18.6$ & $3.6 \pm 11.3$ & $-19.11,26.22$ & $R^{2}=0.72 ; P<0.01$ & $13.2 \pm 12.2$ & $-11.18,37.58$ & $R^{2}=0.60 ; P<0.01$ \\
\hline CT & $78.2 \pm 18.8$ & $6.7 \pm 13.7$ & $-18.33,32.82$ & $R^{2}=0.51 ; P<0.01$ & $16.3 \pm 14$ & $-9.55,43.33$ & $R^{2}=0.50 P<0.01$ \\
\hline $\mathrm{CT}_{\mathrm{LAV}}$ & $79.2 \pm 18.5$ & $5.6 \pm 13.6$ & $-19.39,31.72$ & $R^{2}=0.51 ; P<0.01$ & $15.3 \pm 13.9$ & $-10.56,42.17$ & $R^{2}=0.50 ; P<0.01$ \\
\hline \multicolumn{8}{|l|}{ LLL } \\
\hline S & $91.3 \pm 18.2$ & $-2.7 \pm 13.8$ & $-30.31,25.00$ & $R^{2}=0.61 ; P<0.01$ & $2.5 \pm 10.6$ & $-18.67,23.64$ & $R^{2}=0.69 ; P<0.01$ \\
\hline Q & $90.3 \pm 18.3$ & $-1.7 \pm 15$ & $-31.63,28.15$ & $R^{2}=0.61 ; P<0.01$ & $3.4 \pm 11.9$ & $-20.45,27.26$ & $R^{2}=0.69 ; P<0.01$ \\
\hline
\end{tabular}

Values are represented as mean \pm SD. RUL, right upper lobectomy; RLL, right lower lobectomy; LUL, left upper lobectomy; LLL, left lower lobectomy. COPD, chronic obstructive pulmonary disease; \%DLCO, percent predicted lung diffusion capacity for carbon monoxide; LAV, low-attenuation volume; Limit of agreement, mean \pm 2 SD; M, months; po, postoperative value; ppo, predicted postoperative value.

Anatomically based calculations should be reserved for resections not exceeding one lobe. Fourdrain et al. (3) compared a quantitative CT based ppoFEV ${ }_{1}$, excluding emphysematous lesions, using 19 -segment perfusion and ventilation scintigraphy, the Nakahara formula (25), and the Juhl \& Frost formula (26) based on preoperative spirometry for 23 patients undergoing surgical resection of non-small cell lung cancer (NSCLC), including 18 single and bi-lobectomies and 5 pneumonectomies. Quantitative $\mathrm{CT}$ showed that the mean volume difference of $\mathrm{FEV}_{1}$ between pre-operation and 12 months after surgery was $266 \pm 229 \mathrm{~mL}$, and the highest $\mathrm{R}^{2}(=0.79)$ compared to the other estimation methods. In contrast, Win et al. (6) compared ppoFEV $V_{1}$ estimated by the number of segments and perfusion and ventilation scintigraphy preoperatively and at 18 months after surgery for 61 NSCLC patients undergoing surgical resection, including 56 single lobectomies. They concluded that quantitative ventilationperfusion scintigraphy was not necessary in the preoperative assessment of lung cancer patients undergoing lobectomy.

However, many of these previous studies did not consider whether patients were diagnosed with COPD. The present study suggests that $S$ seems to be a better technique to calculate ppoFEV $V_{1}$ and ppo\%DLCO than the other three techniques for single lobectomy when patients were classified into non-COPD and COPD. 


\section{Comparison between the resected lobes}

Interestingly, the estimation technique that showed the smallest mean difference between ppo and actual postoperative values for $\mathrm{FEV}_{1}$ and \%DLCO were different according to the resected lobe in our study.

At 3 months after lobectomy, the estimation technique that showed the smallest mean differences was Q for RUL, CT and $\mathrm{CT}_{\mathrm{LAV}}$ for RLL, and S for LUL for both FEV and \%DLCO. For LLL, all four techniques provided overestimated ppo values compared to the poFEV 1 and po\%DLCO. At 12 months after lobectomy, those overestimations disappeared for LLL, and CT and $\mathrm{CT}_{\mathrm{LAV}}$ showed the smallest mean differences for both lower lobectomies (LLL and RLL).

The actual po values for $\mathrm{FEV}_{1}$ at 12 months remained smaller than the ppo values calculated by $\mathrm{S}$ for RUL. When the volume of each pulmonary lobe was divided by the number of segmental bronchi, RUL occupied the largest segmental volume compared to the other lobes $(0.31 \pm 0.1 \mathrm{~L})$. The reason may be that $\mathrm{S}$ overestimated the ppo value for RUL.

The smallest mean differences were shown by $\mathrm{Q}$ followed by $\mathrm{CT}_{\mathrm{LAV}}$ for RUL. Obtaining CT imaging is necessary to evaluate lung disease before surgery, but scintigraphy is not. Prediction of postoperative values estimated by quantitative CT, especially with LAV calculation $\left(\mathrm{CT}_{\mathrm{LAV}}\right)$, may be better than $\mathrm{Q}$ even for RUL, because patients sometimes do not agree to more radiation exposure by scintigraphy, and/or due to the lack of scintigrams in the hospital. Win et al. (6) concluded that scintigraphy should be used for further evaluation in patients with quantitative $\mathrm{CT}$ predicted $\mathrm{FEV}_{1}$ in the range of $40 \%$ predicted or lower.

For both $\mathrm{FEV}_{1}$ and \% DLCO, $\mathrm{CT}_{\mathrm{LAV}}$ showed larger ppo values than $\mathrm{CT}$, and $\mathrm{CT}_{\mathrm{LAV}}$ showed smaller mean difference values than CT in both non-COPD and COPD groups, and for any area of lobe resection. In this study, $\mathrm{CT}_{\mathrm{LAV}}$ showed the smallest mean differences for LLL and RLL at 12 months after lobectomy, with smaller \%LAV values than the upper lobes (Table 4). When pulmonary emphysema progresses, airflow limitation increases, and the alveolar gas exchange area decreases because the alveolar wall is destroyed, thus reducing $\mathrm{FEV}_{1}$ and DLCO. In this study, LAV impacted the upper lobes more than the lower lobes (27). RUL and LUL retained two lower lobes with a smaller LAV and one upper lobe with a larger LAV. Subsequently, the upper lobe lobectomy can lose the "worse" lobe, which has increased flow limitation and increased amount of destroyed pulmonary capillary bed, improving their $\mathrm{FEV}_{1}$ and DLCO with expansion and pulmonary capillary recruitment and distension of the remaining "better" lobes (12). This postoperative improvement of pulmonary function may be overlapping the ppo values estimated by volume-based $\mathrm{CT}$ and $\mathrm{CT}_{\mathrm{LAV}}$ technique. In contrast, RLL and LLL retain one "better" lower lobe with smaller LAV and two "worse" upper lobes with larger LAV. In such cases, CT-based techniques may be adequate for estimating ppo values, because flow limitation and diffusion capacity do not improve excessively in lower lobe lobectomy (12).

The present study suggests that $\mathrm{CT}_{\mathrm{LAV}}$ is a better technique to calculate ppoFEV $V_{1}$ and ppo\%DLCO when patients are classified on the basis of the resected lobe. In addition, in case of patients with maldistribution of the lung's blood flow, $\mathrm{Q}$ seems better than $\mathrm{CT}_{\mathrm{LAV}}$ because $\mathrm{CT}$ images show lung volume well, but they do not indicate pulmonary function as $\mathrm{Q}$ does.

\section{Study limitations}

Firstly, the number of patients per lobectomy location was small. The total number of VATS lobectomy has been increasing, but it was not easy to match the number of resected lobes and the number of patients who are diagnosed as non-COPD or COPD using the GOLD classification (16). The current study described the effect of COPD and anatomical location on the ppo values, and a further study with a larger sample size may clarify this effect for the ppo calculation. Secondly, there were no highrisk patients for perioperative mortality $(1,2)$ in this study. Further research is needed to elucidate the relationship between estimation methods and postoperative values according to the resected lobe, complications, or mortality after pulmonary resection in patients with preoperatively lower pulmonary function.

\section{Conclusions}

$\mathrm{S}$ appears to be an adequate method for estimating ppoFEV $_{1}$ and ppo\%DLCO, when patients are classified into non-COPD and COPD groups. However, S sometimes overestimates the ppo values when patients are classified on the basis of the resected lobe. Using an individual estimating method may be necessary for evaluating ppo values associated with the location of the lobe that will be 
resected. The $\mathrm{CT}_{\mathrm{LAV}}$ method may be the method of choice instead of $\mathrm{S}$ for calculating ppoFEV $\mathrm{V}_{1}$ and ppo\%DLCO in patients who undergo lobectomy despite the presence or absence of airflow limitation.

\section{Acknowledgments}

Funding: None.

\section{Footnote}

Reporting Checklist: The authors have completed the STROBE reporting checklist. Available at http://dx.doi. org/10.21037/jtd-20-1280

Data Sharing Statement: Available at http://dx.doi. org/10.21037/jtd-20-1280

Peer Review File: Available at http://dx.doi.org/10.21037/jtd20-1280

Conflicts of Interest: All authors have completed the ICMJE uniform disclosure form (available at http://dx.doi. org/10.21037/jtd-20-1280). The authors have no conflicts of interest to declare.

Ethical Statement: The authors are accountable for all aspects of the work in ensuring that questions related to the accuracy or integrity of any part of the work are appropriately investigated and resolved. The study was conducted in accordance with the Declaration of Helsinki (as revised in 2013). This study was approved by the Kitasato University Medical Ethics Organization on June 28, 2013 (approval KMEO B13-110) and written informed consent was taken from all the patients.

Open Access Statement: This is an Open Access article distributed in accordance with the Creative Commons Attribution-NonCommercial-NoDerivs 4.0 International License (CC BY-NC-ND 4.0), which permits the noncommercial replication and distribution of the article with the strict proviso that no changes or edits are made and the original work is properly cited (including links to both the formal publication through the relevant DOI and the license). See: https://creativecommons.org/licenses/by-nc$\mathrm{nd} / 4.0 /$.

\section{References}

1. Brunelli A, Charloux A, Bolliger CT, et al. ERS/ESTS clinical guidelines on fitness for radical therapy in lung cancer patients (surgery and chemo-radiotherapy). Eur Respir J 2009;34:17-41.

2. Brunelli A, Kim AW, Berger KI, et al. Physiologic evaluation of the patient with lung cancer being considered for resectional surgery: Diagnosis and management of lung cancer, 3rd ed: American College of Chest Physicians evidence-based clinical practice guidelines. Chest 2013;143:e166S-90S.

3. Fourdrain A, De Dominicis F, Lafitte S, et al. Quantitative computed tomography to predict postoperative FEV1 after lung cancer surgery. J Thorac Dis 2017;9:2413-8.

4. Ueda K, Tanaka T, Li TS, et al. Quantitative computed tomography for the prediction of pulmonary function after lung cancer surgery: a simple method using simulation software. Eur J Cardiothorac Surg 2009;35:414-8.

5. Bolliger CT, Guckel C, Engel H, et al. Prediction of functional reserves after lung resection: comparison between quantitative computed tomography, scintigraphy, and anatomy. Respiration 2002;69:482-9.

6. Win T, Laroche CM, Groves AM, et al. Use of quantitative lung scintigraphy to predict postoperative pulmonary function in lung cancer patients undergoing lobectomy. Ann Thorac Surg 2004;78:1215-8.

7. Wu MT, Pan HB, Chiang AA, et al. Prediction of postoperative lung function in patients with lung cancer: comparison of quantitative CT with perfusion scintigraphy. AJR Am J Roentgenol 2002;178:667-72.

8. Suga K, Yasuhiko K, Zaki M, et al. Assessment of regional lung functional impairment with co-registered respiratorygated ventilation/perfusion SPET-CT images: initial experiences. Eur J Nucl Med Mol Imaging 2004;31:240-9.

9. Ueda K, Murakami J, Sano F, et al. Assessment of volume reduction effect after lung lobectomy for cancer. J Surg Res 2015;197:176-82.

10. Korst RJ, Ginsberg RJ, Ailawadi M, et al. Lobectomy improves ventilatory function in selected patients with severe COPD. Ann Thorac Surg 1998;66:898-902.

11. Sengul AT, Sahin B, Celenk C, et al. Postoperative lung volume change depending on the resected lobe. Thorac Cardiovasc Surg 2013;61:131-7.

12. Yokoba M, Ichikawa T, Harada S, et al. Postoperative pulmonary function changes according to the resected lobe: a 1-year follow-up study of lobectomized patients. J 
Thorac Dis 2018;10:6891-902.

13. Japanese Respiratory Society. Guideline for the lung function testing: spirometry, flow-volume curve, diffusion capacity of the lung. Tokyo: Medical Review Co., Ltd., 2004.

14. Kubota M, Kobayashi H, Quanjer PH, et al. Reference values for spirometry, including vital capacity, in Japanese adults calculated with the LMS method and compared with previous values. Respir Investig 2014;52:242-50.

15. Burrows B, Kasik JE, Niden AH, et al. Clinical usefulness of the single-breath pulmonucy diffusing capacity test. Am Rev Respir Dis 1961;84:789-806.

16. Global initiative for Choronic Obstructive Lung Disease (GOLD) guideline. Global Strategy for the Diagnosis, Management, and Prevention of Chronic Obstructive Pulmonary Disease 2018 report. Available online: https:// goldcopd.org/wp-content/uploads/2017/11/GOLD-2018v6.0-FINAL-revised-20-Nov_WMS.pdf, last accessed 6 July 2020.

17. Markos J, Mullan BP, Hillman DR, et al. Preoperative assessment as a predictor of mortality and morbidity after lung resection. Am Rev Respir Dis 1989;139:902-10.

18. Yokoba M, Ichikawa T, Takakura A, et al. Estimated postoperative pulmonary function calculated with lung volume in 3D-CT for lung cancer patients with and without COPD. 1st Asia Oceania Workshop of Pulmonary Functional Imaging combined with 8th Japanese Society of Pulmonary Functional Imaging (1st AOWPFI \& 8th JSPFI)_abstract book. P132, 2016.

19. Bland JM, Altman DG. Statistical methods for assessing agreement between two methods of clinical measurement.

Cite this article as: Yokoba M, Ichikawa T, Harada S, Shiomi K, Mikubo M, Ono M, Sonoda D, Satoh Y, Hanawa H, Naoki K, Katagiri M. Comparison between quantitative computed tomography, scintigraphy, and anatomical methods for prediction of postoperative $\mathrm{FEV}_{1}$ and DLCO: effects of chronic obstructive pulmonary disease status and resected lobes. J Thorac Dis 2020;12(10):5269-5280. doi: $10.21037 /$ jtd-20-1280
Lancet 1986;1:307-10.

20. Kanda Y. Investigation of the freely available easy-touse software 'EZR' for medical statistics. Bone Marrow Transplant 2013;48:452-8.

21. Sansores RH, Pare P, Abboud RT. Effect of smoking cessation on pulmonary carbon monoxide diffusing capacity and capillary blood volume. Am Rev Respir Dis 1992;146:959-64.

22. Graham BL, Brusasco V, Burgos F, et al. 2017 ERS/ATS standards for single-breath carbon monoxide uptake in the lung. Eur Respir J 2017;49:1600016.

23. Kim ES, Kim Y'T, Kang CH, et al. Prevalence of and risk factors for postoperative pulmonary complications after lung cancer surgery in patients with early-stage COPD. Int J Chron Obstruct Pulmon Dis 2016;11:1317-26.

24. Halpin DMG, Decramer M, Celli BR, et al. Effect of a single exacerbation on decline in lung function in COPD. Respir Med 2017;128:85-91.

25. Nakahara K, Monden Y, Ohno K, et al. A method for predicting postoperative lung function and its relation to postoperative complications in patients with lung cancer. Ann Thorac Surg 1985;39:260-5.

26. Juhl B, Frost N. A comparison between measured and calculated changes in the lung function after operation for pulmonary cancer. Acta Anaesthesiol Scand Suppl 1975;57:39-45.

27. Bae K, Jeon KN, Lee SJ, et al. Severity of pulmonary emphysema and lung cancer: analysis using quantitative lobar emphysema scoring. Medicine (Baltimore) 2016;95:e5494. 